\title{
The utility of ultrasound for surgical spinal decompression
}

\author{
Ahmed Alaqeel, ${ }^{1,2}$,Hussam Abou Al-Shaar ${ }^{3}$, Alaa Alaqeel$^{4}$, Amro Al-Habib² $^{2}$ \\ ${ }^{1}$ Department of Neurosurgery, University of Calgary, Calgary, Alberta, Canada, ${ }^{2}$ Division of Neurosurgery, Depart- \\ ment of Surgery, King Saud University, Riyadh, Saudi Arabia, ${ }^{3}$ College of Medicine, Alfaisal University, Riyadh, \\ Saudi Arabia, ${ }^{4}$ College of Medicine, King Saud University, Riyadh, Saudi Arabia
}

\begin{abstract}
Surgery is routinely performed to decompress the spinal cord. While a number of imaging modalities are currently used in the perioperative setting of surgical spinal cord decompression including computed tomography scan and magnetic resonance imaging, ultrasound (US) usage is relatively new. Therefore, only a few studies in the literature describe its value in the perioperative setting. US is a simple, safe, rapid, non-invasive, and inexpensive modality that constitutes a potential alternative when other modalities are not suitable or unavailable. It enables surgeons to generate high-resolution real-time images that can aid in diagnosing pathologies, guiding surgeries, and evaluating surgical outcomes. This review discusses the present literature and utility of pre-, intra-, and post-operative US in patients undergoing surgical spinal decompression. We also delineate three cases in which US was utilized at King Saud University hospital, which is considered one of the first centers in our region to report the use of US to guide treatment in spine surgery.
\end{abstract}

Keywords: ultrasound, spinal cord, compression, surgical decompression

\section{Introduction}

Compression of the spinal cord due to trauma or degeneration can lead to progressive clinical symptoms, such as back pain, numbness, and limb paralysis below the compression site [1]. The posterior arch of the vertebral bone (lamina) can in some cases compress the spinal cord, necessitating removal of the offending section of bone. Surgery is the usual treatment for all types of spinal compression, as pressure on pinched nerves must be relieved to facilitate recovery of spinal cord function [1]. Prior to surgical interventions, neurologists and radiologists commonly employed $\mathrm{X}$-rays, computed tomography (CT) scans, and magnetic resonance imaging (MRI) to guide therapeutic decisions. The introduction of high-res-

Received 19.01.2015 Accepted 16.03.2015

Med Ultrason

2015, Vol. 17, No 2, 211-218

Corresponding author: Ahmed M. Alaqeel, MD

Division of Neurosurgery, Department of Surgery, King Saud University, Riyadh, Saudi Arabia. Department of Neurosurgery, University of algary, Calgary, Alberta, Canada PO Box 285136 Riyadh 11323 Saudi Arabia Phone: +14039709117

E-mail: ahmedalaqeel@hotmail.com olution, real-time ultrasound (US) scanners in the 1980s allowed for the visualization of physiological motion as it happens, which made its utility in the intra-operative setting possible [2]. Since then, US has been routinely used to image the spine in order to assess the effectiveness of decompression and determine the configuration of the spinal cord [3]. Unlike CT scans or X-rays, US does not require the use of potentially dangerous ionizing radiation [4], and it can be used to generate real-time images.

In their review of imaging techniques employed in spinal surgery, Sanders et al [5] identified that imaging strategies should be flexible enough to be used in the pre-, intra-, and post-operative care of patients. Therefore, US needs to meet these criteria in order to establish its benefit over other imaging modalities. In this paper we will discuss the history and the expanding use of US, review the literature on the utilitiy of pre-, intra-, and post-operative US in spinal surgery, and define its efficacy in comparison to other radiographic modalities in such cases.

\section{History of spinal US}

US has been employed as a medical imaging modality since the 1940s, when the introduction of the 'brightness' (B) mode allowed the production of two-dimensional im- 
ages. US uses high-frequency sound waves emitted by a transducer and reflected back from organs and tissues to provide an image on a screen [6]. It was first employed to image breast cancer patients [7]. It is currently commonly utilized to assess fetal growth and morphology, identify tumors, and analyze bone structure. More importantly, because US does not involve the use of ionizing radiation or high power levels that can heat tissue, it poses no known risk to the patient [8]. It was the appearance of real-time US in the 1980s that stimulated surgeons to begin to employ US in diagnosing, evaluating, and guiding the treatment of patients with spinal cord compression.

\section{Pre-operative US}

US is not the technique of choice for pre-operative assessment of spinal cord compression and damage. Although US can sensitively detect incomplete soft tissue injuries [6], MRI is better suited for direct imaging of the spinal cord and the subarachnoid space due to its ability to delineate different tissue types and provide accurate identification of herniations and stenosis in the lumbar and cervical spine [9]. Moreover, MRI can be obtained in multiple planes with different weights, offering a considerable amount of information. However, not all institutions have ready access to CT and MRI equipment, and US can fill this gap. Schwartz [6] presented a case study that demonstrated pre-operative paraspinal US as a viable alternative to MRI. Paraspinal US had an $80 \%$ true positive rate and a $20 \%$ false positive rate. The author concluded that pre-operative diagnostic US represented a good alternative clinical tool when MRI is not deemed suitable.

Moreover, patients who are not candidates to undergo MRI, like patients with implanted devices, such as pacemakers, aneurysm clips, or neurostimulators, as well as those who decline to undergo CT scans, may benefit from US in the pre-operative setting. US is also considered the first-line screening test for neonates and infants $[10,11]$. It does not require sedation or general anesthesia, as it does not mandate the patient to remain still, making it particularly suitable for infants and children. In one study, the authors compared 38 spinal US scans from 30 infants (mean age of 5.5 months) to corresponding MRIs and found that $32 / 38(84 \%)$ of US scans led to the same diagnosis as MRI, 5/38 (13\%) of US scans identified the primary abnormality but missed additional findings revealed by MRI, and 1/38 did not result in consensus [12]. Notably, there were no false positives or negatives.

Another caveat of MRI is that it is usually performed while the patients are lying supine with their hips and knees flexed [13]. This posture can alter spinal canal di- mensions and may mask compression, especially that of nerve roots. Additionally, US may be useful in diagnosing problems associated with standing in some instances.

\section{Intra-operative US}

Although CT and MRI have the upper hand before and after surgery, US is particularly useful during the operation. During spinal procedures and after the removal of the lamina (laminectomy), the US probe can be pointed directly at the area of interest, allowing US scanning to be performed repeatedly throughout the operation to monitor its progress $[14,15]$. Given the US's sensitivity to detect fluid and its movement, it can detect motion of the spinal cord in the cerebrospinal fluid. This is important because it is an indirect index of spinal compression. The arteries that feed the spinal cord are in close proximity to it, and they can also be affected by compression. A compressed spinal cord exhibits high-frequency rhythmic movements that are transmitted from the compressed spinal arteries. Therefore, the magnitude of high-frequency spinal cord motion correlates with the degree and level of compression [16]. Specifically, higher compression is associated with reduced movement. Until the advent of intra-operative US, there was no accurate way to assess this phenomenon as the surgeon's view is limited only to the surgical field. However, with its employment intraoperatively, spinal cord and dura mater motion can be observed with US following laminectomy.

Imamura et al [17] reported the use of US during spinal decompression surgery to generate images of deep-lying structures during anterior cervical surgical approach. These structures are difficult to visualize without US. The authors concluded that US allowed for the optimal approach to be used, resulting in successful spinal decompression with the removal of the posterior longitudinal ligament, which may participate in cord compression in some cases. Lerch et al [18] reported a case study involving 22 patients with traumatic compression (stenosis) of the spinal canal. Intra-operative US was used to control the surgery and the authors concluded that US was an important tool to monitor the spinal canal and to aid in decompression surgery. Others authors have employed intra-operative US for oblique cervical corpectomy (OCC) to treat compressive cervical myelopathy. In one study, a total of 24 patients who underwent OCC were compared to 16 patients who did not have US during surgery [19]. The authors found that US successfully identified the vertebral artery (VA) in all patients, residual cord compression in 6 patients $(27 \%)$, but missed compression in 2 patients $(9 \%)$. They concluded that although intra-operative US was useful for determining the 
location of the VA and the best trajectory for the cervical approach, it had a limited utility in patients with residual ossification causing shadows and/or artefacts.

Some studies have demonstrated the efficacy of intraoperative US in improving patients' outcome. A retrospective study demonstrated that intra-operative US was effective for posterior decompression and instrumented fusion to treat thoracic myelopathy caused by ossification of the posterior longitudinal ligament (OPLL). US use during surgery revealed that although posterior laminectomy was sufficient to decompress the spine of 6 patients, 12 others required additional circumferential intervention [20]. Another study of patients with OPLL described the utility of US in evaluating posterior spinal cord shift following cervical cord surgical decompression [21]. Notably, one group reported that dural pulsation on intraoperative US is not a good indicator of sufficient decompression and should be used in conjunction with other markers of cord compression [22].

Due to its inherent abilities to visualize fluid and its movement, US is useful for intra-operative evaluation of cranio-cervical decompression in patients with Chiari malformation $(\mathrm{CM})$. One study prospectively assessed $16 \mathrm{CM}$ patients with persistent syringomyelia following previous cranio-cervical decompression, in which US was performed during the surgery to observe the cerebellar tonsils and syrinx wall motion, as well as measure the intra-cranial and lumbar intra-thecal pressures before and after opening and placing a graft [23]. The authors reported that US was useful for confirming tonsillar descent in these patients. US can also give neurosurgeons the ability to determine the effectiveness of shunt placement in patients with syringomyelia [14].

In a retrospective Japanese study, the authors assessed the potential of pre-operative radiography to predict spinal cord floating after decompression as shown by intra-operative US [24]. The authors concluded that intra-operative US was superior in predicting the clinical outcome of cervical expansive laminoplasty than postoperative MRI, which is crucial for evaluating the limitations of posterior decompression. Another group that used US to divide patients undergoing indirect posterior decompression with corrective fusion into two groups (floating and non-floating spinal cord) failed to demonstrate a statistically significant difference in outcomes between the two groups [25].

Matsuyama et al [26] used intra-operative US during cervical laminoplasty in 80 consecutive patients with cervical compressive myelopathy to determine whether intra-operative US findings were relevant to pre-operative conditions, assessed by MRI, and post-operative neurological recovery. They used US to classify the patients into four grades according to the restoration pattern of the ventral space to the cord. They also examined cord pulsation and compression type. Their results demonstrated that intra-operative US usage during laminoplasty to correct compressive myelopathy is very useful for confirming spinal cord decompression status. A similar study which evaluated the utility of US in 20 patients with spinal stenosis due to bony fragments or tumors showed that US was useful for delineating the posterior vertebral wall, tumor, and myelopathy, which allowed surgeons to guide their instruments and perform complete cord decompression [27]. Various other studies have also demonstrated that US is particularly useful for confirming optimal decompression intra-operatively [28-30].

US can be applied to other scenarios besides evaluating cord decompression. One report described the utility of intra-operative US to ascertain the bone-removing width and determine whether the remaining material (e.g., posterior lateral osteophytes and hernia prolapse) continued to compress the cord [31]. US is also applicable to spinal trauma patients. The authors of a study involving a group of 39 spinal trauma patients reported that intra-operative US can detect bone fragments, spinal malalignment, cord or thecal sac compression, foreign bodies, and late complications of spinal trauma (e.g., traumatic intramedullary and subarachnoid cysts) [32]. The authors employed US to guide shunting and recommended its routine use in spinal trauma patients.

\section{King Saud University Experience}

At King Saud University we were one of the first centers in our region to use US to guide our surgical treatment plan. This was performed mainly by Dr. Amro Al-Habib and his team at King Saud University, Riyadh, Saudi Arabia. Here we are presenting three educational cases where we used US to guide our surgical plan (fig 1-3).

Comparison of intra-operative US with other intraoperative techniques

It is clear that real-time intra-operative use of MRI and CT scans is not possible due to the inherent nature of these techniques. Myelography is one tool that can be used in the operating suite similarly to US. This method involves the injection of a radiographic contrast medium and subsequent fluoroscopy. It is touted as an intra-operative method that is readily available at most institutions and is less susceptible to the operator variability seen with US [33]. However, in a study performed on 46 cases, the authors concluded that intra-operative US is superior to myelography in patients with thoracolumbar spine fractures. Yet, they underscored the need to complement US with intraoperative X-rays and highly precise pre-operative CT scanning [34]. 


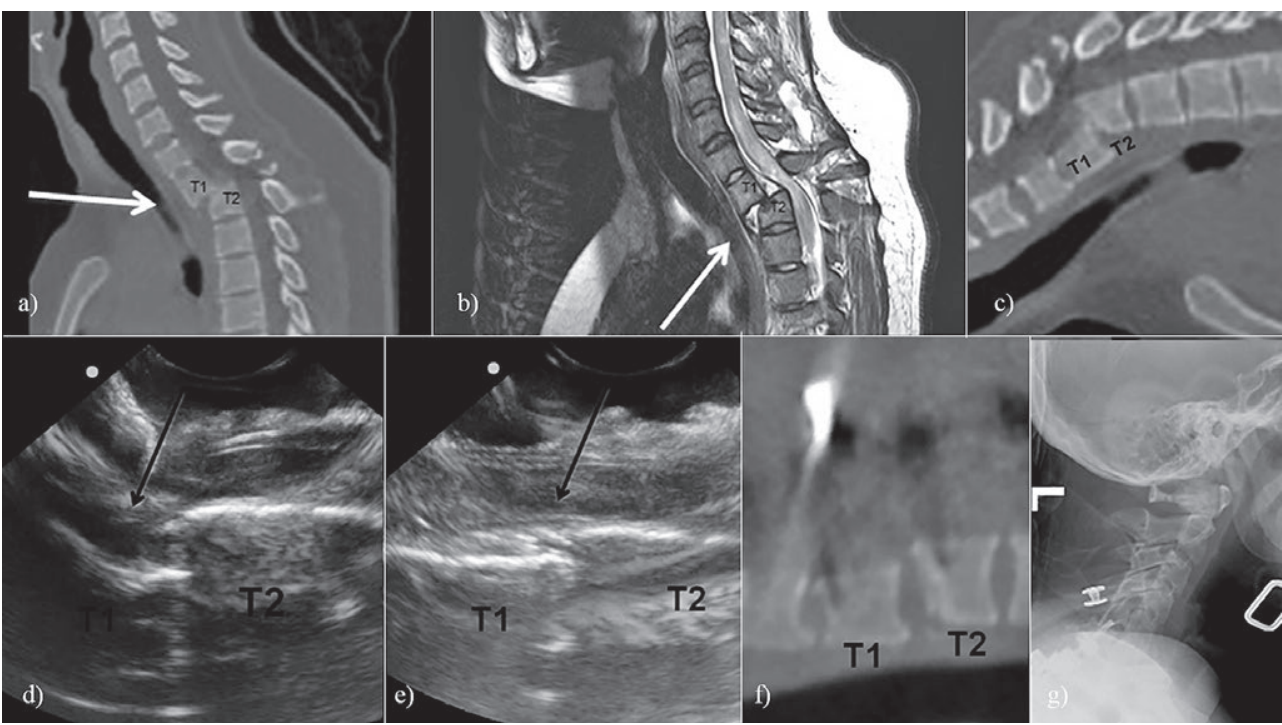

Fig 1. 30-year-old lady involved in a motor vehicle collision. She developed ASIA-A spinal cord injury secondary to T1-2 traumatic subluxation. a, b, c) pre-operative CT and MRI showing T1-2 subluxation; d) Intra-operative US following laminectomy and before reduction confirming subluxation; e) Intra-operative US confirming reduction; f) Postoperative CT showing reduction; g) Intra-operative x-ray was not sufficient to confirm reduction.
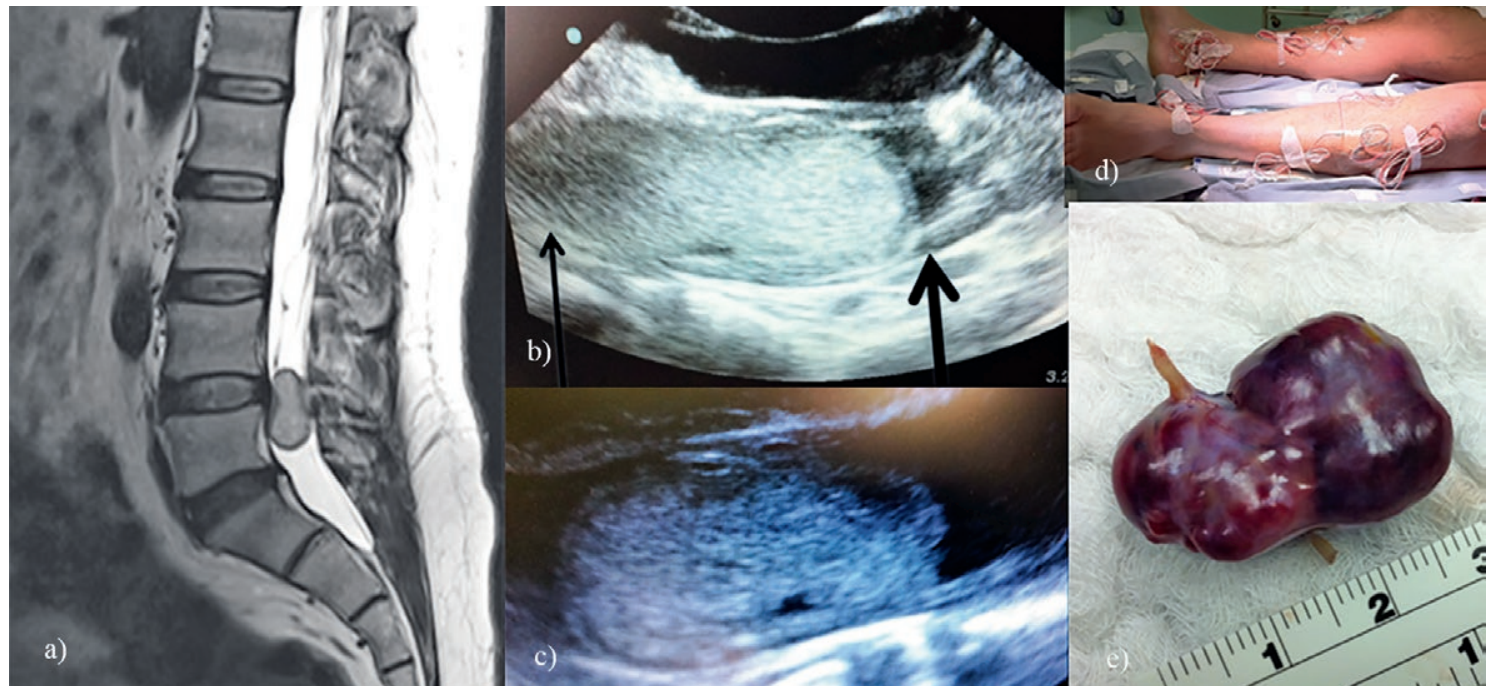

Fig 2. 35-year-old male presented with low back pain. a) Pre-operative MRI showing lumbar intradural tumor; b) Intraoperative US following laminectomy. It showed sufficient exposure above the tumor (thick arrow) but not below it (thin arrow). c) Following more bone exposure, intra-operative US showed adequate tumor exposure prior to dural opening; d) Intra-operative monitoring during surgical resection; e) Total tumor resection. Pathology was consistent with paraganglioma.

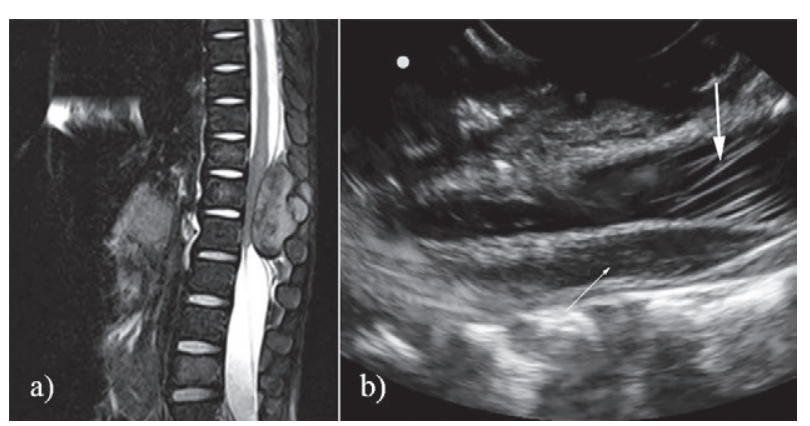

Fig 3. 2.5-year-old girl treated from rhabdomyosarcoma. a) Pre-operative MRI showing lumbar extradural tumor compressing the conus medullaris; b) Intra-operative US following laminectomy and tumor removal confirming normal anatomy of the conus (small arrow) and cauda equina (large arrow). 


\section{Post-operative US}

As in the pre-operative setting, US is not the first-line imaging modality for post-operative imaging in patients able to undergo CT scanning or MRI. However, US is useful in identifying the development of tears, abscesses, and areas of fluid collection after surgery [5,9]. It can also confirm adequate positioning of shunts as well as diagnose tumor recurrence [35]. Kendi et al [36] demonstrated the efficacy of post-operative spinal US in a patient with diastematomyelia and a tethered cord. As described before, US is also an important imaging modality for assessing infants and children who have undergone spinal surgery.

Examples of US efficacy in pre-, intra-, and post-operative spinal surgery are outlined in Table I.

Table I. Advantages of ultrasonography imaging in spinal cord surgery

\begin{tabular}{|c|c|c|}
\hline \multicolumn{3}{|l|}{ Pre-operative } \\
\hline Advantage & Details/Application & References \\
\hline Clear imagery & $\begin{array}{l}\text { - US enables catheter placement in the right jugular vein in preparation for posterior cervi- } \\
\text { cal decompression. } \\
\text { - US has been used to distinguish osseous structures versus paraspinal soft tissue struc- } \\
\text { tures in cadavers. }\end{array}$ & {$[37]$} \\
\hline $\begin{array}{l}\text { Sensitive and specific } \\
\text { method }\end{array}$ & $\begin{array}{l}\text { - US has a sensitivity of } 0.95 \text { and a specificity of } 0.38 \text { for detecting deteriorated disc, } \\
\text { values which are comparable to those achieved with MRI. }\end{array}$ & [39] \\
\hline $\begin{array}{l}\text { Well-established } \\
\text { technique }\end{array}$ & $\begin{array}{l}\text { - US has been used since the } 1940 \text { s when the introduction of 'brightness mode' allowed } \\
\text { for } 2 \text { D representation of tissue samples. } \\
\text { - US has been widely available in most hospitals for over two decades. }\end{array}$ & {$[40]$} \\
\hline Non-invasive & $\begin{array}{l}\text { - US can be used to diagnose spinal conditions in patients where exploratory surgery } \\
\text { would carry an increased risk or in situations where CT scanning or MRI are not available } \\
\text { or suitable. }\end{array}$ & $\begin{array}{l}{[10,11,23,} \\
41,42]\end{array}$ \\
\hline Reliable & - US shows good test-retest reliability for measuring kyphosis within 24 hours. & {$[43]$} \\
\hline Cost-effective & - Diagnostic US is far less expensive than other imaging modalities, such as MRI. & {$[6]$} \\
\hline \multicolumn{3}{|l|}{ Intra-operative } \\
\hline Easy maneuverability & $\begin{array}{l}\text { - US-guided biopsy can be utilized for malignant intramedullary spinal cord lesions and } \\
\text { for subsequent spinal cord decompression assessment. }\end{array}$ & {$[44]$} \\
\hline $\begin{array}{l}\text { High resolution, real- } \\
\text { time imagery }\end{array}$ & $\begin{array}{l}\text { - US visualization can guide successful laminectomy surgeries for spinal decompression } \\
\text { and removal of malignant tumors from the upper cervical spinal cord. } \\
\text { - US can be used to confirm spinal decompression in patients with thoracic and cervical } \\
\text { spondylotic myelopathy and lumbar stenosis. } \\
\text { - US can be used to detect syringomyelia. }\end{array}$ & $\begin{array}{l}{[45]} \\
{[19,22,25,26,} \\
28,29,33,46] \\
{[23]}\end{array}$ \\
\hline Non-invasive & $\begin{array}{l}\text { - US-derived images do not require surgery and the technique can aid minimally-invasive } \\
\text { spinal surgeries. }\end{array}$ & {$[47]$} \\
\hline Rapid & $\begin{array}{l}\text { - US allows surgeons to complete spinal exploration with rapid identification of cysts, } \\
\text { delineation of lesion extent, and in bone fragment localization. } \\
\text { - US can be used effectively in trauma situations. }\end{array}$ & $\begin{array}{l}{[35]} \\
{[32,34]}\end{array}$ \\
\hline $\begin{array}{l}\text { Used with other tech- } \\
\text { niques }\end{array}$ & $\begin{array}{l}\text {-3D-US can be used as a non-invasive technique to build-up an image of the spine work- } \\
\text { ing in tandem with CT scan. } \\
\text { - } 2 \mathrm{D} \text { and } 3 \mathrm{D} \text { laparoscopic US can be used with telerobotics to facilitate autonomous } \\
\text { robotic surgery. } \\
\text { - US can be coupled with CT myelography. }\end{array}$ & $\begin{array}{l}{[47]} \\
{[48]} \\
{[28]}\end{array}$ \\
\hline Able to be optimized & $\begin{array}{l}\text { - Contrast-enhanced US can be used to quantify temporal and spatial changes simultane- } \\
\text { ously in spinal cord blood flow and hemorrhage in a rat animal model. }\end{array}$ & [49] \\
\hline Alternative to MRI & $\begin{array}{l}\text { - MRI is the 'gold standard' for assessing spinal lesions, but US is a comparable alterna- } \\
\text { tive (sensitivity of } 0.99 \text { and specificity of } 0.75 \text { ) and can be used when MRI is not available } \\
\text { or suitable. }\end{array}$ & {$[50]$} \\
\hline $\begin{array}{l}\text { Confirm decompres- } \\
\text { sion during surgery }\end{array}$ & - US is particularly useful for confirming surgical endpoints. & {$[28]$} \\
\hline \multicolumn{3}{|l|}{ Post-operative } \\
\hline $\begin{array}{l}\text { Easy to assess surgi- } \\
\text { cal outcomes }\end{array}$ & $\begin{array}{l}\text { - US can be used to confirm the results of spinal cord surgery. } \\
\text { - US can be used to check post-operative bone defects in patients who have undergone } \\
\text { surgery for meningocele repair. }\end{array}$ & $\begin{array}{l}{[35]} \\
{[36]}\end{array}$ \\
\hline $\begin{array}{l}\text { A routine and flexible } \\
\text { technique }\end{array}$ & $\begin{array}{l}\text { - US can be used to easily check for tears or postoperative infection in patients recovering } \\
\text { from lumbar spine operations. }\end{array}$ & {$[5]$} \\
\hline
\end{tabular}


Conventional surgery to treat spinal compression requires in-depth, intra-operative delineation of the spinal cord and associated vertebrae. In some cases, deep-lying structures are difficult to visualize, and US techniques are necessary to provide high-resolution, real-time images to guide the surgeon during the procedure [51]. Many surgeons have utilized US techniques to measure the diameter of the spinal canal during surgery and evaluate the effectiveness of spinal decompression post-operatively $[23,29,52$ 54]. US has also proved to be invaluable when assessing lumbar disc degeneration, herniation, and muscle tears occurring adjacent to the spinal cord in children [41,42]. The non-invasive nature of US ensures that vulnerable and high-risk patients can be diagnosed and evaluated without the need for exploratory surgery or other invasive measures [10]. The use of US to provide 2D images for surgery has been well established for many decades [6], but the relatively recent development of novel US techniques has resulted in 3D and 4D images with a higher resolution and sensitivity than conventional 2D images. These techniques have been primarily used to monitor fetuses in utero [55], but 3D US imaging, in concert with CT scanning, has now been applied in spinal cord surgeries [47].

The results of reviews, independent assessments, and case studies involving US in patients with spinal cord compression indicate that this technique is useful and improves the care level of patients. The most important aspect of US is the generation of real-time high-quality images which are being further optimized with the development of 3D US techniques. An important aspect for patients is the safety and ease of US procedure. It is a potential alternative to CT scanning, due to its ability to generate images without the need of a radiation source. This is crucial, as radiation exposure should be avoided in young patients due to the increased risks of developing cancer later in life [4]. In addition, US is a potential alternative to MRI in patients who are not candidates for MRI.

The non-invasive nature of US is advantageous for all patients, especially those who are vulnerable to infections, susceptible to blood loss, or those with weakened physical status. It is also useful in assessing spinal cord compression due to hydromyelia or syringomyelia in newborns and should be considered as the first-line imaging modality to investigate spinal cord abnormalities in neonates and children [43]. The comparative mobility of US equipment also allows imaging to be performed at the bedside.

A further important consideration for different visualization techniques is the relative cost. According to Schwartz [6], the use of pre-operative US for the diagnosis of spinal compression is far less expensive than other imaging modalities. Similarly, US equipment is more widely available, even in small hospitals and clinical settings.
However, there are some potential drawbacks of US compared to other imaging techniques. Schwartz [6] noted that much of the controversy surrounding paraspinal US studies has centered on the presence of shadows and artefacts on US images. These artefacts can be especially problematic in patients with high degrees of pathologic ossification [19]. In addition, the technique has received some criticism for the inter-region variability, which depends on the gain setting and angulation of the US transducer [56]. It is clear that, as with other techniques, the precision of US imaging is limited by the expertise of the handler. It is essential to have a considerable level of skill to obtain high-quality images with US.

Intra-operatively, surgeons must be experienced in interpreting US images in order to make accurate interventional decisions. Nazarian et al [57] described high false-positive rates as well as high rates of imaging artefacts associated with US techniques. It should be noted, however, that Schwartz [6] claimed that protocols have been established to minimize echo artefacts and shadows in order to improve reproducibility between operators. If these protocols are followed closely, the effectiveness of diagnostic paraspinal US can increase tremendously.

\section{Conclusions}

The use of US in creating real-time images of spinal cord anatomy and pathologic conditions in spinal cord decompression surgeries provides a potential alternative to other imaging techniques. The existing scientific literature clearly describes key roles for US in diagnosing and treating spinal cord compression as well as its utility in evaluating the efficacy of decompression postoperatively. US is much less expensive than CT scanning and MRI, and is not associated with radiation exposure. However, it is essential to have appropriate US equipment and well trained operators in order to optimize penetration depth into spinal cord structures and avoid misinterpreting echo artefacts and shadows, respectively. Finally, given that US has only been used in this capacity for approximately 30 years, future technical developments will increase the utility of this modality in aiding various spinal surgeries.

\section{Acknowledgment}

This study was funded by the College of Medicine Research Center, Deanship of Scientific Research, King Saud University.

Conflict of interest: none 


\section{References}

1. Matz PG, Pritchard PR, Hadley MN. Anterior cervical approach for the treatment of cervical myelopathy. Neurosurgery 2007; 60(1 Supp1 1): S64-S70.

2. Dohrmann GJ, Rubin JM. Use of ultrasound in neurosurgical operations: a preliminary report. Surg Neurol 1981; 16: 362-366.

3. Dohrmann GJ, Rubin JM. History of intraoperative ultrasound in neurosurgery. Neurosurg Clin N Am 2001; 12: 155-166, ix.

4. Smith-Bindman R, Lipson J, Marcus R, et al. Radiation dose associated with common computed tomography examinations and the associated lifetime attributable risk of cancer. Arch Intern Med 2009; 169: 2078-2086.

5. Sanders WP, Truumees E. Imaging of the postoperative spine. Semin Ultrasound CT MR 2004; 25: 523-535.

6. Schwartz RG, Rohan J, Hayden F. Diagnostic Paraspinal Musculoskeletal Ultrasonography. J Back Musculoskelet Rehabil 1999; 12: 25-33.

7. Wild JJ, Reid JM. Application of echo-ranging techniques to the determination of structure of biological tissues. Science 1952; 115: 226-230.

8. Hangiandreou NJ. AAPM/RSNA physics tutorial for residents. Topics in US: B-mode US: basic concepts and new technology. Radiographics 2003; 23: 1019-1033.

9. Thakkar RS, Malloy JP 4th, Thakkar SC, Carrino JA, Khanna AJ. Imaging the postoperative spine. Radiol Clin North Am 2012; 50: 731-747.

10. Unsinn KM, Geley T, Freund MC, Gassner I. US of the spinal cord in newborns: spectrum of normal findings, variants, congenital anomalies, and acquired disease. Radiographics 2000; 20: 923-938.

11. Dick EA, Patel K, Owens CM, De Bruyn R. Spinal ultrasound in infants. Br J Radiol 2002; 75: 384-392.

12. Rohrschneider WK, Forsting M, Darge K, Tröger J. Diagnostic value of spinal US: comparative study with MR imaging in pediatric patients. Radiology 1996; 200: $383-$ 388.

13. Saifuddin A, Blease S, MacSweeney E. Axial loaded MRI of the lumbar spine. Clin Radiol 2003; 58: 661-671.

14. Rubin JM, Dohrmann GJ. The spine and spinal cord during neurosurgical operations: real-time ultrasonography. Radiology 1985; 155: 197-200.

15. Rubin JM, Chandler WF. The use of ultrasound during spinal cord surgery. World J Surg 1987; 11: 570-578.

16. Jokich PM, Rubin JM, Dohrmann GJ. Intraoperative ultrasonic evaluation of spinal cord motion. J Neurosurg 1984; 60: 707-711.

17. Imamura H, Iwasaki Y, Hida K, Cho KH, Abe H. Intraoperative spinal sonography in the cervical anterior approach. Neurol Med Chir (Tokyo) 1995; 35: 144-147.

18. Lerch K, Völk M, Heers G, Baer W, Nerlich M. Ultrasoundguided decompression of the spinal canal in traumatic stenosis. Ultrasound Med Biol 2002; 28: 27-32.

19. Moses V, Daniel RT, Chacko AG. The value of intraoperative ultrasound in oblique corpectomy for cervical spondy- lotic myelopathy and ossified posterior longitudinal ligament. Br J Neurosurg 2010; 24: 518-525.

20. Tian W, Weng C, Liu B, et al. Intraoperative 3-dimensional navigation and ultrasonography during posterior decompression with instrumented fusion for ossification of the posterior longitudinal ligament in the thoracic spine. J Spinal Disord Tech 2013; 26: E227-E234.

21. Seichi A, Chikuda H, Kimura A, et al. Intraoperative ultrasonographic evaluation of posterior decompression via laminoplasty in patients with cervical ossification of the posterior longitudinal ligament: correlation with 2-year follow-up results. J Neurosurg Spine 2010; 13: 47-51.

22. Kimura A, Seichi A, Inoue H, et al. Ultrasonographic quantification of spinal cord and dural pulsations during cervical laminoplasty in patients with compressive myelopathy. Eur Spine J 2012; 21: 2450-2455.

23. Heiss JD, Suffredini G, Smith R, et al. Pathophysiology of persistent syringomyelia after decompressive craniocervical surgery. Clinical article. J Neurosurg Spine 2010; 13: 729-742.

24. Naruse T, Yanase M, Takahashi H, et al. Prediction of clinical results of laminoplasty for cervical myelopathy focusing on spinal cord motion in intraoperative ultrasonography and postoperative magnetic resonance imaging. Spine (Phila Pa 1976) 2009; 34: 2634-2641.

25. Matsuyama Y, Sakai Y, Katayama Y, et al. Indirect posterior decompression with corrective fusion for ossification of the posterior longitudinal ligament of the thoracic spine: is it possible to predict the surgical results? Eur Spine J 2009; 18: 943-948.

26. Matsuyama Y, Kawakami N, Yanase M, et al. Cervical myelopathy due to OPLL: clinical evaluation by MRI and intraoperative spinal sonography. J Spinal Disord Tech 2004; 17: 401-404.

27. Lerch K, Völk M, Neumann C, Nerlich M. Intraoperative spinal sonography. Ultraschall Med 2002; 23: 113-118.

28. Matsuyama Y, Kawakami N, Mimatsu K. Spinal cord expansion after decompression in cervical myelopathy. Investigation by computed tomography myelography and ultrasonography. Spine (Phila Pa 1976) 1995; 20: 1657-1663.

29. Kawakami N, Mimatsu K, Kato F, Sato K, Matsuyama Y. Intraoperative ultrasonographic evaluation of the spinal cord in cervical myelopathy. Spine (Phila Pa 1976) 1994; 19: 34-41.

30. Wang YQ, Liu XG, Jiang L, et al. Intraoperative ultrasonography in "cave-in" $360^{\circ}$ circumferential decompression for thoracic spinal stenosis. Chin Med J (Engl) 2011; 124: 3879-3885.

31. Yamaoka K. Significance of intraoperative ultrasonography in anterior spinal operation. Spine (Phila Pa 1976) 1989; 14: 1192-1197.

32. Montalvo BM, Quencer RM, Green BA, Eismont FJ, Brown MJ, Brost P. Intraoperative sonography in spinal trauma. Radiology 1984; 153: 125-134.

33. Pao JL, Wang JL. Intraoperative myelography in minimally invasive decompression for degenerative lumbar spinal stenosis. J Spinal Disord Tech 2012; 25: E117-E124. 
34. Lazennec JY, Sailland G, Ramare S, Hansen S. Intraoperative ultrasound study of thoracolumbar spinal fractures with spinal canal fragments. Determining canal width and anatomic control of decompression: comparative analysis with CT. Unfallchirurg 1998; 101: 353-359.

35. Pasto ME, Rifkin MD, Rubenstein JB, Northrup BE, Cotler JM, Goldberg BB. Real-time ultrasonography of the spinal cord: intraoperative and postoperative imaging. Neuroradiology 1984; 26: 183-187.

36. Kendi T, Bademci G. Postoperative spinal ultrasonography findings in spinal dysraphia. Diagn Interv Radiol 2005; 11: 142-144.

37. Szkup PL. A minimally invasive technique for closing an iatrogenic subclavian artery cannulation using the Angio-Seal closure device: two case reports. J Med Case Rep 2012; 6: 82.

38. Lebkowska U, Lebkowski WJ. Visualisation of the model of human lumbosacral spine in ultrasound examination. Ann Med Univ Bialyst Pol 1993; 38: 100-106.

39. Tervonen O, Lähde S, Vanharanta H. Ultrasound diagnosis of lumbar disc degeneration. Comparison with computed tomography/discography. Spine (Phila Pa 1976) 1991; 16: 951-954.

40. Koivukangas J, Tervonen O. Intraoperative ultrasound imaging in lumbar disc herniation surgery. Acta Neurochir (Wien) 1989; 98: 47-54.

41. Harlow CL, Drose JA. A special technique for cervical spine sonography. Illustrated by a patient with meningoencephalocele, Dandy-Walker variant, and syringomyelia. J Ultrasound Med 1992; 11: 502-506.

42. Naidich TP, Fernbach SK, McLone DG, Shkolnik A. John Caffey Award. Sonography of the caudal spine and back: congenital anomalies in children. AJR Am J Roentgenol 1984; 142: 1229-1242.

43. Fölsch C, Schlögel S, Lakemeier S, Wolf U, Timmesfeld N, Skwara A. Test-retest reliability of 3D ultrasound measurements of the thoracic spine. PM R 2012; 4: 335-341.

44. Lieberson RE, Veeravagu A, Eckermann JM, et al. Intramedullary spinal cord metastasis from prostate carcinoma: a case report. J Med Case Rep 2012; 6: 139.

45. Miranpuri AS, Rajpal S, Salamat MS, Kuo JS. Upper cervical intramedullary spinal metastasis of ovarian carcinoma: a case report and review of the literature. J Med Case Rep 2011; 5: 311 .
46. Goto S, Mochizuki M, Kita T, et al. Anterior surgery in four consecutive technical phases for cervical spondylotic myelopathy. Spine (Phila Pa 1976) 1993; 18: 1968-1973.

47. Barratt DC, Penney GP, Chan CS, et al. Self-calibrating 3D-ultrasound-based bone registration for minimally invasive orthopedic surgery. IEEE Trans Med Imaging 2006; 25: 312-323.

48. Leven J, Burschka D, Kumar R, et al. DaVinci canvas: a telerobotic surgical system with integrated, robot-assisted, laparoscopic ultrasound capability. Med Image Computing and Computer-Assisted Intervention 2005; 8: 811-818.

49. Soubeyrand M, Laemmel E, Dubory A, Vicaut E, Court C, Duranteau J. Real-time and spatial quantification using contrast-enhanced ultrasonography of spinal cord perfusion during experimental spinal cord injury. Spine (Phila Pa 1976) 2012; 37: E1376-1382.

50. Vordemvenne T, Hartensuer R, Löhrer L, Vieth V, Fuchs T, Raschke MJ. Is there a way to diagnose spinal instability in acute burst fractures by performing ultrasound? Eur Spine J 2009; 18: 964-971.

51. Raynor RB. Intraoperative ultrasound for immediate evaluation of anterior cervical decompression and discectomy. Spine (Phila Pa 1976) 1997; 22: 389-395.

52. Finlay D, Stockdale HR, Lewin E. An appraisal of the use of diagnostic ultrasound to quantify the lumbar spinal canal. Br J Radiol 1981; 54: 870-874.

53. Portela LA. Sonography of the normal and abnormal intact lumbar spinal canal. AJR Am J Roentgenol 1985; 144: 386390.

54. St Amour TE, Rubin JM, Dohrmann GJ. The central canal of the spinal cord: ultrasonic identification. Radiology 1984; 152: 767-769.

55. Kurjak A, Miskovic B, Andonotopo W, Stanojevic M, Azumendi G, Vrcic H. How useful is 3D and 4D ultrasound in perinatal medicine? J Perinat Med 2007; 35: 10-27.

56. Aldrete J, Vandenberg B, Rairdain W. Use of ultrasound as an adjunct to locate anatomical landmarks in regional anesthesia. Regional Anesthesia 1992; 17: 57.

57. Nazarian LN, Zegel HG, Gilbert KR, Edell SL, Bakst BL, Goldberg BB. Paraspinal ultrasonography: lack of accuracy in evaluating patients with cervical or lumbar back pain. $\mathrm{J}$ Ultrasound Med 1998; 17: 117-122. 